\title{
Health financing and catastrophic payments for health care: evidence from household-level survey data in Botswana and Lesotho
}

\author{
Oluyele Akinkugbe (Department of Economics, University of Namibia, Windhoek, Namibia) \\ Chitalu Mirriam Chama-Chiliba (Department of Economics, University of Pretoria, Pretoria 0002, \\ South Africa) \\ Naomi Tlotlego (Department of Economics, University of Pretoria, Pretoria 0002, South Africa)
}

\begin{abstract}
The financing of health care is a complex issue for policy makers. This is because high out-ofpocket payments on health care have been found to further impoverish the poor who have limited income to divide among basic necessities of which health care is one-catastrophic health expenditure (CHE). The Millennium Development Goals (MDGs) may be difficult to attain with high out-of-pocket payments by the poor; this is an issue of serious concern and highlights the need for the kind of analyses in this paper. The analysis used data collected by the Household and Expenditure Survey (HIES) 2002/2003 for Botswana and by the Household Budget Survey (HBS) 2002/2003 for Lesotho. Our results showed that in Botswana the proportion of households facing CHE at the $20 \%$ and $40 \%$ thresholds was $11 \%$ and $7 \%$ respectively, and the share of out-of-pocket health payment during the survey period was about $0.93 \%$. For Lesotho the proportions of those facing CHE expenditure at the $20 \%$ and $40 \%$ thresholds were $3.22 \%$ and $1.25 \%$, and the share of out-of-pocket payment in total monthly expenditure was $1.34 \%$. Results from regression analyses suggest that having at least one senior member in the household imposes a higher risk for CHE for the household in Lesotho; for Botswana gender and education status of households head influence the probability of facing CHE. In designing health systems, policy makers need to ensure that households are not only able to access health services when needed, but that they are also protected from facing financial catastrophe by reducing out-of-pocket payments.
\end{abstract}

\section{Introduction}

The financing of health systems in a country has profound effects on its population's access to healthcare and the health status of its citizens. One of the challenges common to health systems in developing countries is achieving fairness in the distribution of the financing burden, and the protection of households from the risk of financial loss (WHO, 2000). ${ }^{i}$ Hence, in recent times, much of the public discourse in countries undertaking health sector reform is focused on designing a health financing system and achieving fairness. In most of sub-Saharan Africa, Botswana and Lesotho included, many households, especially poor ones, are not part of any form of medical insurance scheme. They therefore have to spend a substantial share of their income for health services to the extent that they are driven further into poverty. This situation 
makes it impossible for World Health Organization (WHO) member states to attain their target goals of health for all, equity and fairness in financing the health system.

The foregoing discussion highlights the challenges facing sub-Saharan African policy makers. To be able to design the financing of an efficient and fair health system as part of the ongoing drive towards achieving the Millennium Development Goals (MDGs) by 2015, these policy makers need to know what characteristics make households more vulnerable to health payments, and how these can lead to reduced welfare and impoverishment. If not adequately addressed, the declining welfare that results from an unfair system of financing health systems may further deepen societal inequality.

The situation in the last couple of decades has been one in which interventions in the health care system in sub-Saharan Africa reduced the ability of the poor and near-poor to seek health care services. This inability to seek health care by the poor, who constitute the majority of the population in most low income countries, implies reduced productivity in the economy, shortened working lives, and an increased number of days lost to illness. All these may mean reduced income-generating ability on the part of already poor households, who may then have to sell assets to pay for treatment or abstain from seeking care, compounding poverty and powerlessness, and further increasing ill-health. This could lead to reduced growth prospects for the economy.

This paper assesses the degree of inequality in the distribution of health expenditures across income quintiles in Botswana and Lesotho. Furthermore, it examines the characteristics of households which face health payments that have an impoverishing effect on their welfare, that is, for which high out-of-pocket payments and by implication high household financial contribution to health induces catastrophic payments. ${ }^{\text {it }}$ According to the growing literature on inequality in financial contribution to health in low income countries, for catastrophic health expenditure (CHE) to arise three factors have to be present: the availability of health services that require out-of-pocket payments; low household capacity to pay; and the lack of pre-payment mechanisms for risk pooling (WHO, 2005). The simplest indicator of inequality in health financing is high out-of-pocket payments relative to household capacity to pay which similarly implies the presence of catastrophic expenditure in the health care system. Reducing inequalities of this nature is widely perceived as intrinsically important as a development goal. However, 
inequalities in health financing reflect and reinforce inequalities in other domains, and these inequalities together act as a brake on economic growth and development (World Bank, 2006).

\section{Literature review}

Catastrophic payment occurs when out-of-pocket payments for health care cross some threshold share of household total expenditure (Berki, 1986; Wyszewianski, 1986; Pradhan and Prescott, 2002; Wagstaff and van Doorslaer, 2003; Xu et al., 2003a, 2003b). While it is acknowledged that the choice of threshold is arbitrary, $10 \%$ of total expenditure has been a common choice (Pradhan and Prescott, 2002; Ranson, 2002; Wagstaff and van Doorslaer, 2003). The rationale is that this represents an approximate threshold at which the household is forced to sacrifice other basic needs, sell productive assets, incur debt or be impoverished (Russell, 2004).

The 2000 World Health Report suggested that households for which the fairness in financing ratio exceeded 0.5 would be likely to be impoverished as a result of high levels of health spending relative to capacity to pay (World Health Organisation, 2000). iii Following this approach, Kawabata et al. (2002) propose that health expenditures should be termed catastrophic when they exceed $40 \%$ of a household's capacity to pay. Following the same approach Xu et al. (2003a, 2003b) used cross-sectional data from 59 countries to analyse the prevalence and causes of catastrophic health spending. They find that the proportion of households incurring catastrophic health spending is $10.3 \%$ in Brazil, $0.1 \%$ in Costa Rica, 1.5\% in Mexico, 2.1\% in Nicaragua, 2.4\% in Panama, 3.5\% in Paraguay, and 3.2\% in Peru. Van Doorslaer et al. (2007) looked at catastrophic spending in 10 Asian territories. They found relatively low rates in Malaysia, Sri Lanka and Thailand and relatively high rates in China, Viet Nam and Bangladesh. The study by van Doorslaer et al. (2007) also looked at the pre-payment income distribution of those experiencing catastrophic payments. For the most part, catastrophic spending was concentrated among the better off although this was said to be dependent to some degree on the threshold chosen.

Related research includes a study from PAHO (2003) that analyses in detail the factors leading to a lack of financial, physical and cultural access to health services in Latin American countries. Combining measures of health insurance coverage, out-of-pocket health spending as a percentage of income, and public health care spending, the study finds that the proportion of populations without real health care coverage is $20.7 \%$ in Ecuador, $33.0 \%$ in Guatemala, 39.3\% in Honduras, $47 \%$ in Paraguay, 31\% in Peru, and 20.0\% in the Dominican Republic. 
Several previous studies (multi-country and within-country) have shown that in some countries, all families, including the poor, spend a high share of their budget on out-of-pocket health spending (Van Doorslaer et al., 1993; Hotchkiss et al., 1998; Wagstaff et al., 1999; WHO, 2004, 2005; Xu et al., 2005; Chama, 2008). In Thailand and Mexico, the poor were found to spend a higher proportion of their income on out-of-pocket health spending than the rich. Further, the regressivity of out-of-pocket spending is related to the degree to which populations are covered by pre-paid insurance schemes, (Frenk, et al., 1994; Pannarunothai and Mills, 1997). In addition, out-of-pocket payments are regressive in a number of countries, and exacerbate the existing inequalities in the distribution of income (Gonzalez and Parker, 1999; Lasprilla, et al., 1999; Suarez, 1999; Valladares and Barillas, 1999).

A comparative study carried out in 10 Organisation for Economic Co-operation and Development (OECD) countries showed that the most inequitable health financing system favouring the rich is found in the countries with high reliance on private insurance and out-ofpocket payments, such as in the United States and Switzerland (Merlis ,2002). An analysis of different sources of health care payments indicated that out-of-pocket health care payments were particularly regressive. High-income groups spent proportionally less than their share of total income, and lower income groups spent proportionally more than their share of total income (Van Doorslaer and Wagstaff., 1992; Wagstaff et al., 1999).

Several studies also examined the characteristics of the health systems which protect households from catastrophic expenditures or the factors that lead some households to face such payments whilst others are protected. Merlis (2002) and Wysewianski (1986) found that households headed by older people with disabilities, the unemployed or the poor, and those with reduced access to health insurance were more likely to be affected than other households. Pannarunothai and Mills (1997) and Skarbinski et al. (2002) found that the poor in Thailand were more likely to have to pay for health services from their own household income than richer people which, when combined with lower incomes, places these people at higher risk of catastrophic health payments.

O'Donnell et al. (2008), in a multi-country study of Asian countries, investigated the sources of variation across households in the incidence of catastrophic expenditures. The study concentrated on a 10\% threshold which is argued to proximate the burden at which a household is forced to sacrifice other basic needs, deplete productive assets, incur debt or be impoverished. Sources of variation in the incidence of catastrophic payments were examined by defining a dummy variable equal to one if out-of-pocket payments for health care exceeded $10 \%$ of the 
household budget and regressing this on covariates using the probit model. The study found that the probability of incurring catastrophic payments increases with increasing total household expenditure.

Within country studies conducted in Lebanon, Indonesia and Uganda using household surveys and logistic regression analysis to investigate the determinants of catastrophic health expenditures indicate that in all 3 countries, more than 3\% of the households face catastrophic expenditure. In Lebanon and Indonesia $1.6 \%$ and 1.8\% of the households respectively were driven into poverty as a result of these catastrophic expenditures while in Uganda $2.2 \%$ were pushed into poverty. All the studies found that households with senior members and less healthy family members were at a higher risk of facing catastrophic expenditures whilst those who were in urban areas and had bigger families were at a lower risk.

Similarly, Flessa (2006) found that $5 \%$ to $6 \%$ of total households incurred catastrophic expenditure in Nouna District in Burkina Faso even at low levels of health care utilization and modest amount of health expenditure. The key factors that contributed to these catastrophic expenditures were economic status, household health care utilization especially for modern care, illness episodes in an adult household member and presence of a member with chronic illness. Further, recent studies in Zambia (Chama, 2008; Cheelo et al., 2009) using household survey data found that households without a working head, those in the lower quintile and those living in urban areas were more likely to suffer from catastrophic expenditures. The studies found that about $2 \%$ of the households were facing catastrophic expenditures and about $1 \%$ were consequently pushed into poverty.

The Wagstaff and Doorslaer (2003) study on the incidence and intensity of catastrophic expenditure in Vietnam for the period 1993-1998 found that both the incidence and intensity fell, whether defined in terms of pre-payment income or ability-to-pay. The incidence and intensity also became concentrated among the poor, though the poverty impact of out-of-pocket payments tends to diminish over time.

Several studies explore how policies and institutions affect the incidence of catastrophic health spending. Xu et al. (2003a, 2003b, , 2005, 2007) found that rates of catastrophic spending are higher in poorer countries and in those with limited pre-payment systems. The most recent study by Xu et al. (2007) (controlling for whether pre-payment as a share of health spending exceeds $50 \%$ ) found that the incidence of catastrophic spending does not vary between tax-financed or social health insurance systems. Looking at cross-country differences, van Doorslaer et al. (2007) 
speculate that the low incidence of catastrophic spending in Sri Lanka, Malaysia and Thailand reflects the low reliance on out-of-pocket spending to finance health care and limited use of user fees in the public sector. In contrast, the high incidence rate in the Republic of Korea is argued to reflect the high copayments in that country's social insurance system and the partial coverage of inpatient care. De Graeve and Van Ourti (2003) found that the incidence of catastrophic spending in Belgium would have been higher without a policy that imposes a ceiling on official out-of-pocket payments linked to a family's income. This ceiling has the greatest effect in the middle of the income distribution.

Several country level studies have also concluded that insurance reduces the risk of catastrophic spending. Gakidou et al. (2006) and Knaul et al. (2006) found that after Mexico introduced the Popular Health Insurance scheme in 2001 the incidence of catastrophic health expenditures reduced. Limwattananon et al. (2007) found that rates of catastrophic spending in Thailand were lower after the country introduced the universal health care scheme in 2001. Habicht et al. (2006) found that the risk of catastrophic spending in Estonia increased during the late 1990s and early 2000s. They attribute this partly to rising copayments (hence a decrease in the depth of coverage) linked to a decline (in real terms) in government health spending and partly to the ageing of the population—elderly people have shallower coverage, especially for medicines.

Xu et al. (2005) found lower rates of catastrophic out-of-pocket spending among the Ugandan population after user fees were removed in 2001, although the rate increased among the poor. They speculate that this was due to the frequent unavailability of drugs at government facilities following the removal of user fees-patients were then forced to buy drugs from private pharmacies and/or make informal payments to health workers to offset lost revenues from fees. Ekman (2007) found that insurance increases the risk of catastrophic spending in Zambia and suggests that the amount of care per illness episodes may have increased. He contends that quality assurance and the oversight of service providers is important in determining how far insurance reduces the risk of catastrophic spending.

From the foregoing, there appears to be cross-country variation in the prevalence and distribution of catastrophic payments that seems to be attributable to differences in national income, financing structure and user charging policy. Economic development is certainly an important determinant of the degree to which household welfare is put at risk by health payments, but no law condemns the households of low-income countries to suffer financial hardship because of these payments. Some countries, such as Malaysia, the Philippines, Sri Lanka and Thailand have managed to contain the out-of-pocket health financing share below the 
average level at their national incomes. In contrast, Bangladesh, China, India and Vietnam, stand out in relying heavily on out-of-pocket financing and having a high incidence of catastrophic payments. While the second group of countries is, in general, poorer, there is, for example, little difference between the average incomes of China and Sri Lanka.

To investigate the impoverishment effect of high out-of-pocket, Van Doorslaer et al. (2006b) used data from 11 Asian countries to compare pre- and post-payment poverty head counts and poverty gaps using the World Bank's dollar-a-day poverty line (as well as its US\$2-a-day poverty line). On average, they found that the dollar-a-day poverty head count is almost three percentage points higher when out-of-pocket spending is deducted from household consumption. The difference is almost 4 percentage points in Bangladesh and India, but just 0.1 and 0.3 percentage points in Malaysia and Sri Lanka respectively.

Along the same line, Alam et al. (2005) compared pre- and post-payment poverty head counts in 10 countries in Eastern Europe and the former Soviet Union using a US\$2.15-a-day poverty line at 2000 prices and purchasing power parities. On average, out-of-pocket payments raise the poverty head count by two percentage points-Armenia (3.4), Georgia (3.6) and Tajikistan (3.3) recorded the highest increases. These authors found that the average share of income spent on out-of-pocket health care payments is quite different in Armenia (around 12\%) and Georgia (around 7\%). However, the shares among the poorest and second quintiles are quite similar at around $14 \%$ and $8 \%$ respectively. The high rates of impoverishment due to health care spending in these countries likely reflects the collapse of publicly-financed health systems and increasing reliance on out-of-pocket payments, including informal ones. The rate in Armenia would probably have been even higher if the government's 2001 reform had not provided the services in the health insurance scheme's benefit package free of charge to households receiving social assistance.

\section{Method of analysis}

Drawing mainly from the WHO methodology (Xu et al., 2003a, 2003b) to assess catastrophic health payments and the extent of impoverishment that derives from such high out-of-pocket payments, this paper examines the fairness in health financing in Botswana and Lesotho. In this regard, some objectivity in the measurement of catastrophic out-of-pocket health payment is introduced by defining it as out of pocket that results in the deprivation of the consumption of necessities. Doing this, we retain the assumption of earlier studies that health expenditure is involuntary. This assumption means that out-of-pocket health expenditure has an entirely 
negative effect on household welfare, as it deprives households of resources that could have been spent on other essential goods and services.

CHE was calculated from national representative data derived from the Household and Expenditure Survey (HIES) 2002/2003 for Botswana and from the 2002/2003 Household Budget Survey (HBS) for Lesotho. In both countries, the estimation size of the surveys was designed to represent rural and urban settlements and data was collected on socioeconomic and demographic characteristics as well as household expenditures. For Lesotho, the survey was conducted on 6,882 households from the 2002/2003 survey, while for Botswana it was conducted on 6,053 households.

In both countries, the items under which data on expenditures were collected for comprised payments made for food, non-food (such as electricity, education, alcoholic beverages, clothing, tobacco, health care) and other goods and services by households to meet their daily needs. These were categorized into expenditures for food and non-food. The aggregate between the food and non-food was taken to represent total consumption expenditure. The out-of-pocket payments were payments made for medical products, appliances, services and for medical expenditure made in the preceding six months for which households will not be reimbursed by medical aid schemes.

The logistic regression technique was used to analyse the determinants of CHE using household survey data in Botswana and Lesotho. The dependant variable, CHE (defined based on two alternative threshold levels of $40 \%$ and $20 \%$ ) is a binary outcome defined as 1 when the household faces catastrophic health expenditures and 0 otherwise. The basic unit of analysis in this study was the household. Given that the dependant variable, CHE (defined based on two alternative threshold levels, cata1 and cata2) is a binary outcome, a latent variable with a dichotomous realization is specified and forms the basis for the use of logistic regression analysis. The logistic regression modelling technique was based on the assumption that the error term follows a logistic distribution. Thus, the latent variable with a dichotomous realization was specified on the dependant variable as follows:

$$
\begin{array}{ll}
\text { Cata }=1 & \text { if } y^{*}>0 \\
\text { Cata }=0 & \text { otherwise }
\end{array}
$$


The model is then specified in general as:

$\mathrm{y}^{*}=\alpha+\sum \beta_{i} \mathrm{X}_{\mathrm{i}}+\varepsilon$

Where $\mathrm{y}^{*}$ is the dependant variable, $\alpha$ is the constant and $\mathrm{X}_{\mathrm{i}}$ the independent variables and $\beta_{\mathrm{i}}$ the coefficients being estimated.

This general specification is further specified as an empirical form pursuant to the construction of variables. Using logistic regression analysis, the empirical specification is used in the separate estimation of each threshold level, cata1 and cata2.

\subsection{Data sources and summary description ${ }^{\text {iv }}$}

As earlier indicated, the analysis was based primarily on the most recent representative surveys conducted in Botswana and Lesotho by the respective central statistical offices (CSO).

The HIES and the HBS provide information on a host of issues and variables, which include demographic, health, education, household expenditure, household access to various amenities and facilities, etc. The surveys also contain information at both individual and household levels. At individual levels the data include socioeconomic information (such as age, sex, education, urban/rural location etc.) and health service utilization, whereas at household level the information contained in the surveys includes total household consumption expenditure, food expenditure, non-food expenditures (includes tobacco and alcohol, which should be excluded in the construction of subsistence expenditure, out-of-pocket health expenditure, private health insurance spending etc.

\subsection{Data analysis}

CHE was calculated from national representative data derived from HIES 2002/2003 and from HBS 2002/2003 for Botswana and Lesotho respectively. In both countries, the estimation size of the surveys was designed to represent rural and urban settlements and data were collected on socioeconomic and demographic characteristics and household expenditures. Monthly household expenditures were used in the analysis for both Botswana and Lesotho. ${ }^{\text {vi }}$ 
A household's financial contribution through out of pocket that is equal to or greater than $40 \%$ of its capacity to pay was considered catastrophic. To measure the household's capacity to pay, total expenditure (reported as food plus non-food expenditure) was used. Capacity to pay was computed as what the household had after meeting the minimum required costs to maintain basic life. Subsistence expenditure was calculated by multiplying poverty line with household size adjusted for consumption -equivalents in the household. A household was classified as poor if its consumption expenditure was less than subsistence expenditure, and considered impoverished if after paying for health care, it could not meet the minimum requirement of basic needs to sustain life.

To examine determinants of CHE in Botswana and Lesotho, bivariate analysis was used and only those variables which were significant were used for regression analysis in the Botswana regression model. For Botswana, gender of household head, education, employment and marital status, household size and place of residence were found to be significant and therefore included in the model. For Lesotho only age 5, age65, residence and gender of household head were used in the model.

\section{Estimation results}

According to the Botswana HIES 2002/2003, about $7 \%$ and $11 \%$ of households spent $40 \%$ or $20 \%$ or more of their monthly expenditure respectively, as out-of-pocket health payment and thus faced catastrophic payments (Table 1). In Lesotho (Table 2), the results indicate that about $1 \%$ and $3 \%$ of households were faced with catastrophe as a result of spending $40 \%$ and $20 \%$ or more respectively of their monthly income. The proportion of households facing $\mathrm{CHE}$ at the $40 \%$ threshold were $1.6 \%, 1.6,1.1 \%, 1.1 \%$ and $0.9 \%$ from the poorest to richest respectively in Lesotho. For Botswana, the proportions of households facing CHE were higher at 13.3\%, $12.5 \%, 6.8 \%, 4.4 \%$ and $0.1 \%$ respectively at the $40 \%$ threshold. At the $20 \%$ threshold, the proportions were higher in both cases, as expected.

Before making health payments, about $35 \%$ of households in Lesotho were poor. About $21 \%$ of the households in Lesotho were impoverished after making health payments and these were from the poorest to the fourth quintile. No household from the richest quintile was impoverished as result of health payments. 


\section{Table 1: Distribution of some household characteristics across the expenditure quintiles, Botswana}

\begin{tabular}{|c|c|c|c|c|c|c|}
\hline \multirow[b]{3}{*}{ Characteristics } & \multicolumn{5}{|c|}{ Expenditure quintiles } & \multirow{3}{*}{ Total } \\
\hline & Quintile & Quintile & Quintile & Quintile & Quintile & \\
\hline & 1 & 2 & 3 & 4 & 5 & \\
\hline Average $\mathrm{HH}$ total expenditure & 721.4317 & 1621.653 & 2886.202 & 6072.242 & 21644.34 & 6589.17 \\
\hline Average $H H$ capacity to pay & 42.66 & 161.01 & 349.69 & 1063.96 & 15499.23 & 3423.31 \\
\hline Average $H H O O P$ bealth payments & 7.4 & 17.75 & 24.45 & 52.03 & 224.06 & 65.14 \\
\hline$O O P$ health expenditure share $(\%)^{a}$ & 1.07 & 1.04 & 0.84 & 0.87 & 0.86 & 0.93 \\
\hline OOP health expenditure share in capacity to pay (\%) & 13.13 & 13.12 & 8.06 & 6.31 & 1.44 & 8.41 \\
\hline Poor Households (\%) & 100 & 100 & 100 & 64.17 & 100 & 92.83 \\
\hline Households with CHE ( $\geq 20 \%)$ & 16.59 & 16.19 & 12.68 & 9.16 & 0.87 & 11.1 \\
\hline Households with CHE ( $\geq 40 \%)$ & 13.34 & 12.5 & 6.81 & 4.43 & 0.07 & 7.43 \\
\hline Impoverishment (\%) & 100 & 100 & 100 & 0.8 & 100 & 80.16 \\
\hline
\end{tabular}

$a=$ expenditure was calculated for the whole year and not monthly; OOP = out of pocket; $\mathrm{HH}=$ household. Note: Figures are in Botswana Pula.

\section{Table 2: Distribution of some household characteristics across the expenditure quintiles, Lesotho}

\begin{tabular}{lllllll}
\hline & \multicolumn{7}{l}{ Expenditure quintiles } & & \\
\cline { 2 - 5 } & Quintile & Quintile & Quintile & Quintile & Quintile & \\
Characteristics & $\mathbf{1}$ & $\mathbf{2}$ & $\mathbf{3}$ & $\mathbf{4}$ & $\mathbf{5}$ & Total \\
\hline Average HH total expenditure & 153.28 & 353.91 & 585.77 & 959.47 & 2193.69 & 849.22 \\
Average HH capacity to pay & 56.54 & 145.1 & 278.73 & 605.57 & 1836.96 & 584.58 \\
Average HH OOP health payments & 1.35 & 4.03 & 7.64 & 14.55 & 47.59 & 15.03 \\
OOP health expenditure share in total monthly & & & & & & \\
expenditure (\%) & 0.79 & 1.18 & 1.33 & 1.54 & 1.85 & 1.34 \\
OOP share of capacity to pay (\%) & 1.93 & 2.64 & 2.56 & 2.33 & 2.24 & 2.34 \\
Poor households (\%: poor before health payments) & 100 & 73.71 & 0 & 0 & 0 & 34.74 \\
Households with CHE ( $\geq 20 \%)$ & 2.98 & 3.73 & 3.62 & 3.14 & 2.63 & 3.22 \\
Households with CHE ( $\geq 40 \%)$ & 1.57 & 1.58 & 1.09 & 1.07 & 0.93 & 1.25 \\
Impoverished households (\%) & 100 & 2.65 & 0.84 & 0.17 & 0 & 20.73 \\
\hline
\end{tabular}

OOP = out of pocket; $\mathrm{HH}=$ household.

Note: Figures are in Lesotho Maloti. 
Table 3: Bivariate analysis of some household characteristics in relation to catastrophic health expenditure for Botswana

\begin{tabular}{|c|c|c|c|c|c|c|}
\hline Household characteristics & $\begin{array}{l}\text { Household faced } \\
\text { catastrophic } \\
\text { health } \\
\text { expenditure, Per } \\
\text { cent (N=6,053) } \\
\text { (40\% threshold) }\end{array}$ & $\begin{array}{l}\text { Chi- } \\
\text { square }\end{array}$ & $p$ & $\begin{array}{l}\text { Household faced } \\
\text { catastrophic } \\
\text { health } \\
\text { expenditure, Per } \\
\text { cent (N=6,053) } \\
\text { (20\% threshold) }\end{array}$ & $\begin{array}{l}\text { Chi- } \\
\text { square }\end{array}$ & $p$ \\
\hline & $\%$ & & & $\%$ & & \\
\hline Expenditure quintiles & & 238.62 & 0.00 & & 232.76 & 0.00 \\
\hline Quintile1 (poorest) & 13.40 & & & 16.59 & & \\
\hline Quintile2 & 12.50 & & & 16.19 & & \\
\hline Quintile3 & 6.81 & & & 12.68 & & \\
\hline Quintile4 & 4.43 & & & 9.16 & & \\
\hline Quintile5 (richest) & 0.07 & & & 0.87 & & \\
\hline Gender of $\mathrm{HH}$ head & & 9.95 & 0.00 & & 19.06 & 0.00 \\
\hline Male & 5.58 & & & 8.57 & & \\
\hline Female & 7.59 & & & 11.97 & & \\
\hline $\begin{array}{l}\text { Educational status of } \mathrm{HH} \\
\text { head }\end{array}$ & & 92.40 & 0.00 & & 90.27 & 0.00 \\
\hline Non-formal & 7.83 & & & 15.65 & & \\
\hline Primary & 8.33 & & & 12.65 & & \\
\hline Secondary & 2.17 & & & 5.03 & & \\
\hline $\begin{array}{l}\text { Employment status of } \mathrm{HH} \\
\text { head }\end{array}$ & & 79.31 & 0.00 & & 66.77 & 0.00 \\
\hline Not employed & 11.15 & & & 15.34 & & \\
\hline Employed & 4.79 & & & 8.19 & & \\
\hline Marital status of $\mathrm{HH}$ & & 17.61 & 0.00 & & 16.01 & 0.00 \\
\hline Single & 5.49 & & & 8.81 & & \\
\hline Married & 6.43 & & & 10.16 & & \\
\hline Divorced & 9.79 & & & 13.84 & & \\
\hline Residence & & 121.52 & 0.00 & & 76.79 & 0.00 \\
\hline Rural & 11.75 & & & 15.30 & & \\
\hline Cities/towns & 3.15 & & & 6.90 & & \\
\hline Urban villages & 7.49 & & & 10.95 & & \\
\hline Household size & & 31.61 & 0.00 & & 34.04 & 0.00 \\
\hline 4 or less & 8.93 & & & 8.46 & & \\
\hline 5 or more & 5.19 & & & 13.21 & & \\
\hline
\end{tabular}

The monthly share of out-of-pocket payments expenditure showed a rising trend from the poorest to the richest. In absolute terms, the out-of-pocket payments spent on health in Botswana among the poorest was about one-eighth that spent by the richest, whilst in Lesotho, 
Table 4: Bivariate analysis of some household characteristics in relation to catastrophic health expenditure for Lesotho ${ }^{1}$

\begin{tabular}{|c|c|c|c|c|c|c|}
\hline \multirow[t]{2}{*}{ Household characteristics } & $\begin{array}{l}\text { Household faced } \\
\text { catastrophic health } \\
\text { expenditure, Per cent } \\
(\mathrm{N}=5,991)(40 \% \\
\text { threshold })\end{array}$ & $\begin{array}{l}\text { Chi- } \\
\text { square }\end{array}$ & $p$ & $\begin{array}{l}\text { Household faced } \\
\text { catastrophic health } \\
\text { expenditure, Per cent (N } \\
=5,991)(20 \% \text { threshold) }\end{array}$ & $\begin{array}{l}\text { Chi- } \\
\text { square }\end{array}$ & $p$ \\
\hline & $\%$ & & & $\%$ & & \\
\hline Expenditure quintiles & & 3.54 & 0.47 & & 3.16 & 0.53 \\
\hline Quintile 1 (poorest) & 1.57 & & & 2.98 & & \\
\hline Quintile 2 & 1.58 & & & 3.73 & & \\
\hline Quintile3 & 1.09 & & & 3.62 & & \\
\hline Quintile 4 & 1.07 & & & 3.14 & & \\
\hline Quintile 5 (richest) & 0.93 & & & 2.63 & & \\
\hline Gender of HH head & & 0.00 & 0.96 & & 0.10 & 0.75 \\
\hline Male & 1.25 & & & 3.97 & & \\
\hline Female & 1.26 & & & 3.32 & & \\
\hline Educational status of HH head & & 4.04 & 0.26 & & 3.03 & 0.39 \\
\hline None & 1.38 & & & 3.41 & & \\
\hline Primary & 1.12 & & & 3.01 & & \\
\hline Secondary & 0.52 & & & 2.25 & & \\
\hline Tertiary & 1.72 & & & 3.88 & & \\
\hline Source of income & & 2.56 & 0.46 & & 4.18 & 0.24 \\
\hline Public & 0.99 & & & 2.36 & & \\
\hline Private & 1.03 & & & 2.83 & & \\
\hline Farming & 1.60 & & & 3.58 & & \\
\hline Other & 1.26 & & & 3.58 & & \\
\hline $65+$ member living in $\mathrm{HH}$ & & 2.66 & 0.10 & & 5.11 & 0.02 \\
\hline No & 1.12 & & & 2.94 & & \\
\hline Yes & 1.68 & & & 4.17 & & \\
\hline$\geq 5$ member living in $\mathrm{HH}$ & & 2.65 & 0.10 & & 1.60 & 0.21 \\
\hline No & 1.45 & & & 3.46 & & \\
\hline Yes & 0.97 & & & 2.88 & & \\
\hline Size of $H H$ & & 3.03 & 0.08 & & 4.38 & 0.04 \\
\hline 5 or less & 1.43 & & & 3.56 & & \\
\hline 6 or more & 0.90 & & & 2.55 & & \\
\hline Residence & & 0.10 & 0.76 & & 0.06 & 0.81 \\
\hline Urban & 1.30 & & & 3.28 & & \\
\hline Rural & 1.21 & & & 3.17 & & \\
\hline Marital Status & & 2.41 & 0.30 & & 0.80 & 0.67 \\
\hline Single/Never married & 1.40 & & & 2.57 & & \\
\hline Married/ living together & 1.05 & & & 3.19 & & \\
\hline Divorced/separated/widowed & 1.52 & & & 3.39 & & \\
\hline
\end{tabular}

${ }^{7}$ The authors were unable to secure more comprehensive data for Lesotho and therefore had to use what was available.

the amount spent by the poorest was about one-tenth that spent by the richest. This depicts a clear gradient across the expenditure quintiles. 
Table 5: Determinants of CHE in the logistic regression model (40\% and $20 \%$ threshold) for Botswana

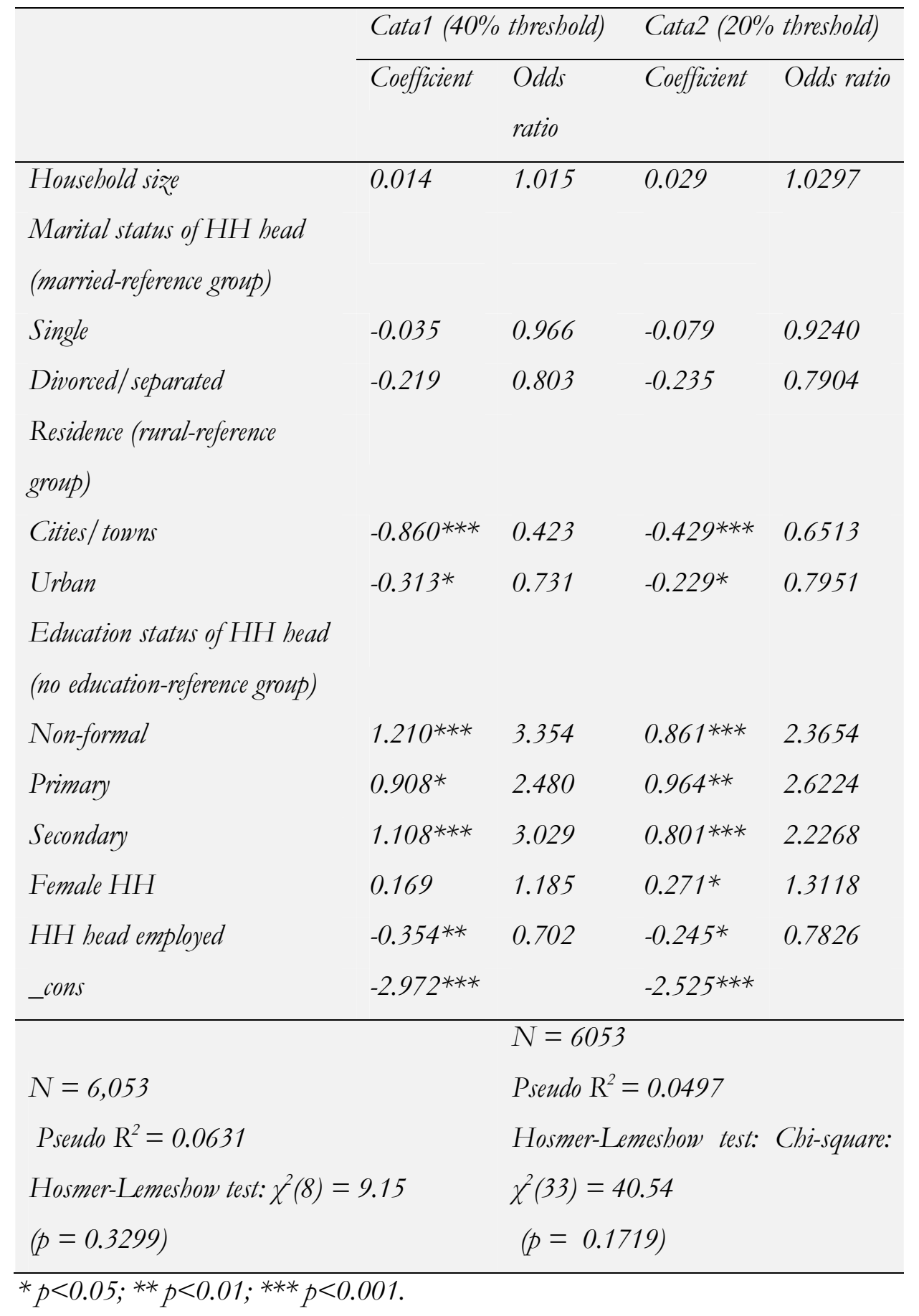

The results of the bivariate chi-square analysis are shown in Tables 3 and 4 for Botswana and Lesotho respectively. In Botswana (Table 3), the poorer quintiles were found to have proportionately more households who were likely to face $\mathrm{CHE}$ and this was significant for both the $20 \%$ and $40 \%$ thresholds. However, in Lesotho (Table 4), the results for CHE amongst 
expenditure quintiles were found to be statistically insignificant. Household head characteristics such as education, employment status, household size, residence and gender were statistically significant for Botswana. Only the household size and whether a household had a senior member or not (age65) were significant in Lesotho. All variables that were found to be significant in the bivariate analysis (except expenditure quintile) were included in the logistic regression for Botswana. For Lesotho the variables age5, age65, household size, residence and gender of household were included in the model.

To explore the determinants of catastrophic health expenditures for households in the two countries, a logistic regression analysis was used. The binary independent variable is defined as 1 when the household's expenditure is equal to or above the either the $40 \%$ or $20 \%$ threshold of its capacity to pay. The unit of analysis was the household. The results are presented in Tables 5 and 6. In Table 5 (for Botswana), the results show that a wide range of factors were associated with CHE.

Table 6: Determinants of CHE in the logistic regression model (40\% and $20 \%$ threshold) for Lesotho

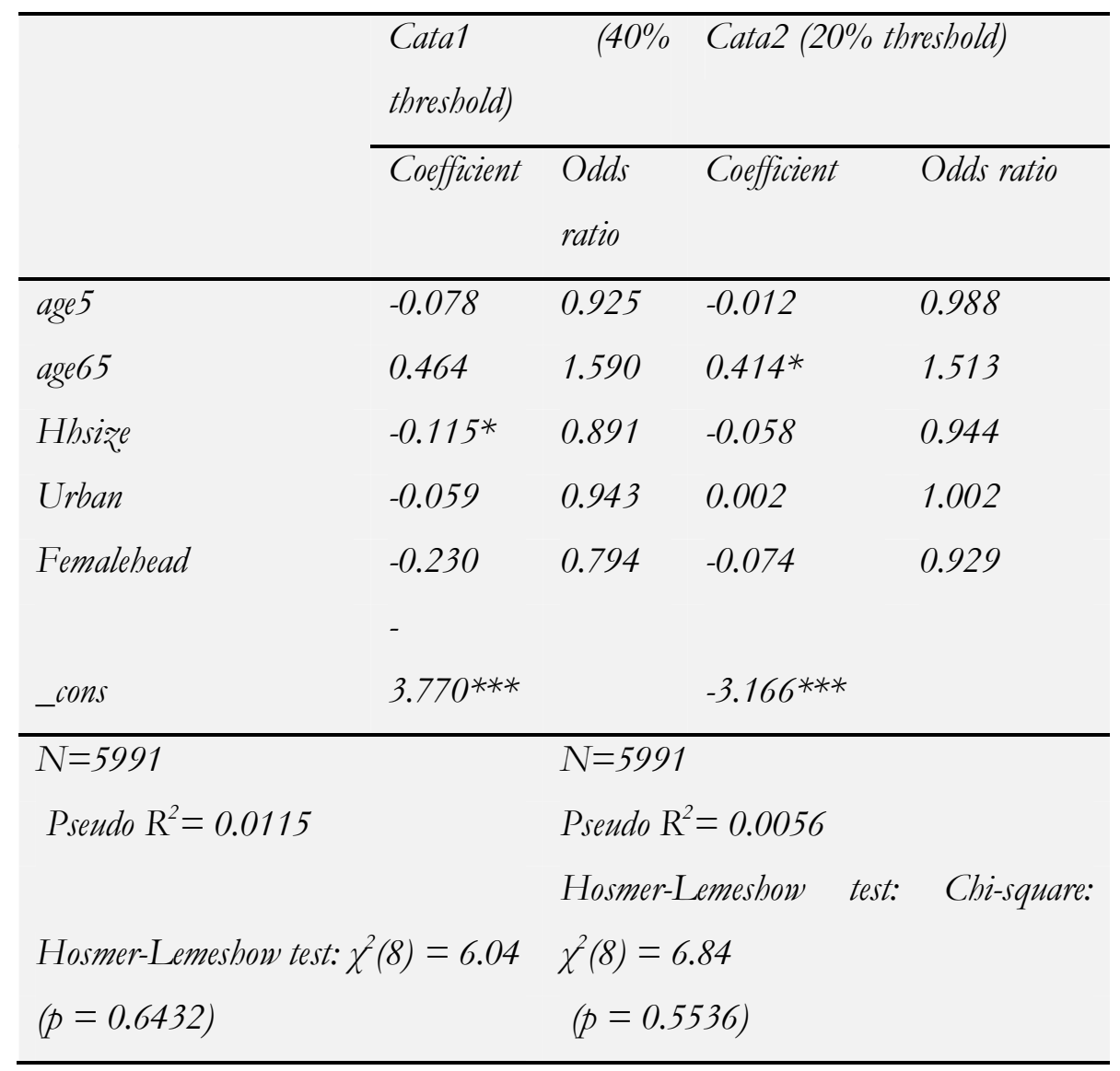


The results suggest that in Botswana households in the rural areas were more likely to face CHE than their counterparts in cities/towns and urban areas were. In addition, households with a head who was unemployed were more likely to face CHE. At the $20 \%$ per cent threshold, female headed households and households with an educated head were less likely to face CHE. In Lesotho only the household size and presence of a senior member in the household increased the risk of catastrophe.

Figure 1: Concentration curves-Botswana

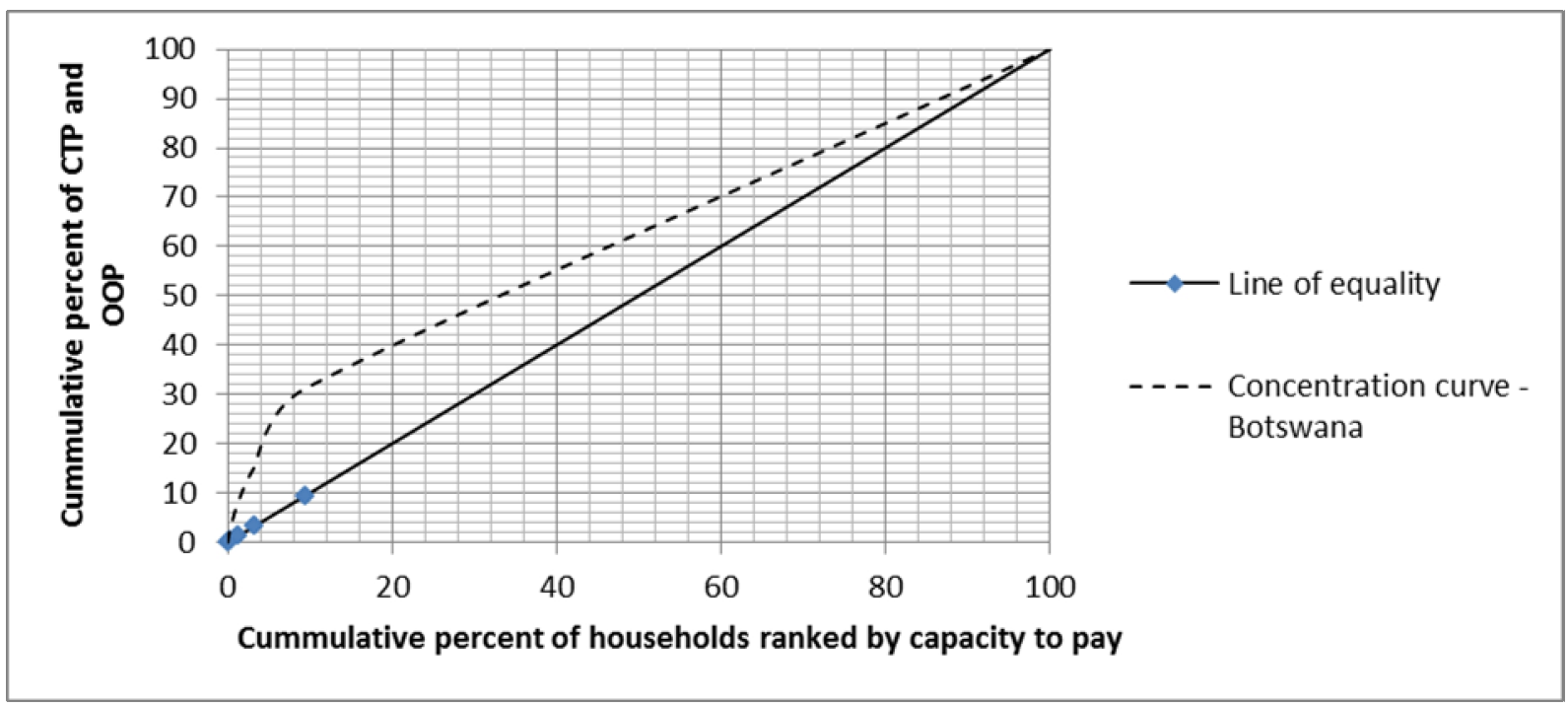

Note: Pro-poor-concentration curve statistically dominates (lies above) the $45^{\circ}$ line of equality. Pro-richconcentration curve is statistically dominated by the $45^{\circ}$ line. Equality-concentration curve is statistically indistinguishable from the $45^{\circ}$ line.

Figure 2: Concentration curves-Lesotho

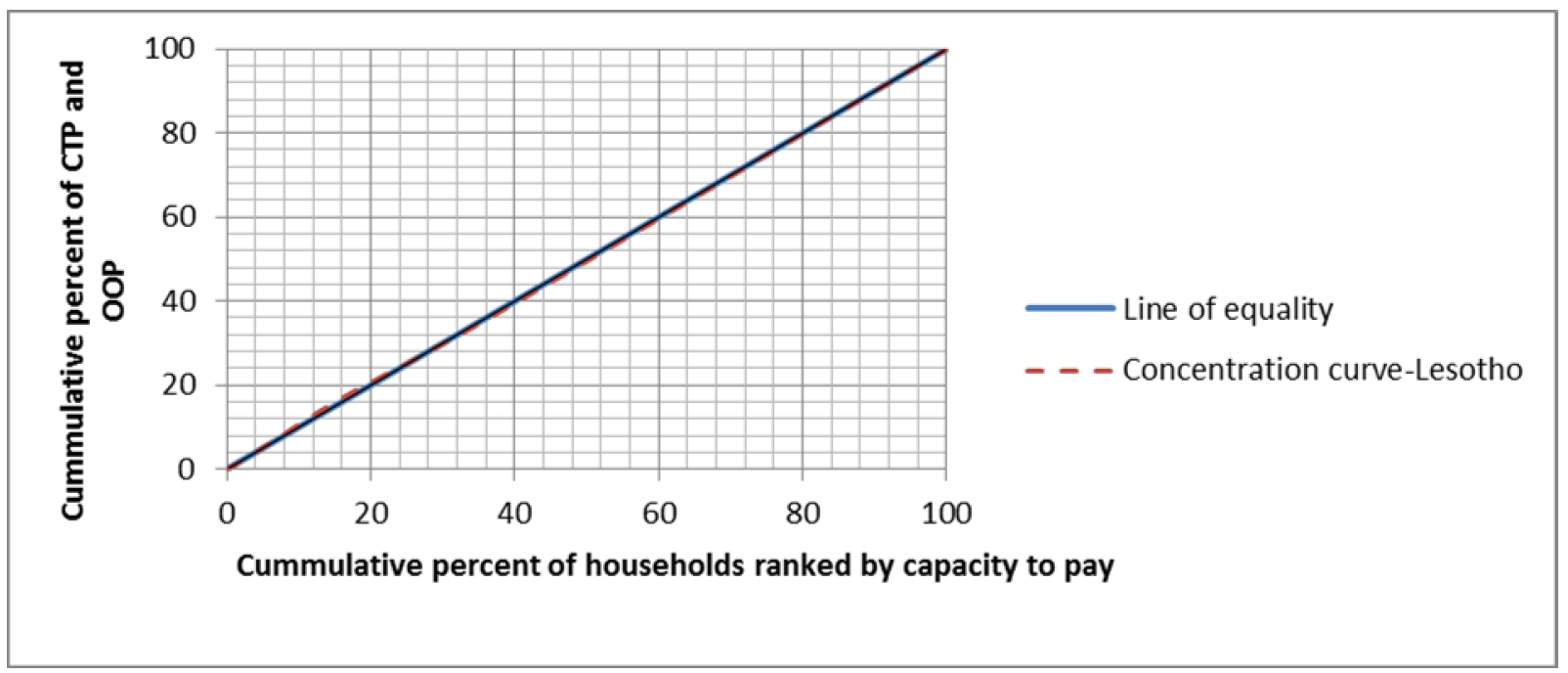

Note: Pro-poor-concentration curve statistically dominates (lies above) the $45^{\circ}$ line of equality. Pro-richconcentration curve is statistically dominated by the $45^{\circ}$ line. Equality-concentration curve is statistically indistinguishable from the $45^{\circ}$ line. 
The concentration curve for Botswana (Figure 1) lies above the line of equality, indicating that health care payments are concentrated among the poor. For Lesotho the concentration curve (Figure 2) is almost super-imposed on the line of equality. This may be an indication that health payments between the rich and poor in Lesotho do not vary much. The computation of the fairness in financial contribution (FFC) indices for Lesotho and Botswana rendered 0.85 and 0.62 respectively. This further shows that the Lesotho health system was relatively more fair than that of Botswana. An index close to one indicates that a health system is fair and one that is close to zero suggests an unfair system.

As a caveat, note that the results of our analysis should be interpreted with caution since out-ofpocket payments in Botswana were spread over 12 months. It would have been interesting, however, if out-of-pocket expenditures had been collected monthly for a year to observe how the proportion of those facing CHE would compare to the out-of-pocket share in total monthly expenditure in the country. This would clearly indicate the user's share in health payments which is crucial in terms of fairness of financing.

\section{Conclusion and lessons}

Financing of health care is a complex issue for policy makers, given its implications on fairness and inequity in the system. Embedded in the notions of fairness in financing is the much needed step towards preventing financial impoverishment of poor households when one of the members becomes ill. In light of the MDGs which may not be attainable with high out-ofpocket payments by the poor and near-poor for health care, the emerging trend for governments in developing countries is to move away from out-of-pocket to pre-payment schemes or health insurance. This is because out-of-pocket spending on health care has been found to further impoverish the already poor who have limited income to divide among basic necessities of which health care is just one. This study found that in Lesotho, for example, about $21 \%$ of households become impoverished after they make health payments. In Botswana, however, about $80 \%$ of households are impoverished after making such payments. Due to data limitations, the study could not establish whether the impoverishment was permanent or transitory; these results should therefore be interpreted with caution. However, it is certain that high out-of-pocket payment constitutes a risk factor for poorer households.

To ascertain the importance of a user's share to health payments, which is crucial in terms of fairness in financing, we compared the proportion of households facing CHE to the proportion of out-of-pocket health spending share in total expenditure for both countries. In Botswana the 
proportion of households facing CHE at the $20 \%$ and $40 \%$ thresholds was $11 \%$ and $7 \%$ respectively while the share of out-of-pocket health payment for the year under survey was about $0.93 \%$. For Lesotho the proportions of those facing CHE expenditure and the share of out-ofpocket health expenditure share in total monthly expenditure at the $20 \%$ and $40 \%$ threshold was $3.22 \%$ and $1.25 \%$, while the share of out-of-pocket in total monthly expenditure was $1.34 \%$.

Furthermore, the results from the regression for Lesotho suggest that having at least one senior member in the household imposes a higher risk for catastrophic health expenditure for the household. This implies that elderly people are the most vulnerable and could face financial hardship due to out-of-pocket payments. In Botswana gender and education status of household head influenced the probability of facing catastrophic health payments. Female-headed and more educated household heads were less likely to face financial catastrophe. This highlights the importance of education in addressing issues related to health payments.

In designing health care systems, policy makers need to ensure that households are not only able to access health services when needed, but that they are also protected from facing the financial catastrophe occasioned by high out-of-pocket. The results from this study offer some suggestions for evidence based interventions that might help reduce the prevalence of $\mathrm{CHE}$ particularly in Botswana.

As previously discussed, the issues of inequity and fairness or otherwise in health financing, and the prevalence of catastrophic health payments are closely linked to poverty, and failure of the social security system to pool funds in low income countries. The share of the population facing catastrophic payments is a function of the poverty level, insufficient pooling, and the utilization of services. Our analyses in this report seem to also suggest that the main reason for the observed high percentage of households making catastrophic payments in Botswana and Lesotho is the prevalence of out-of-pocket payments for physician services and pharmaceuticals.

Another factor that seems to affect fairness in health financing is the structure of the existing health care system in Botswana and Lesotho; it provides coverage mainly to the section of the population with paid (official) employment. The self-employed, agricultural workers and smallscale farmers and other informal sector operatives (usually the larger segment of the population), do not contribute or have no obligation to pay any social contributions to the system. This situation opposes the principle of social cohesion as it tends to be skewed in favour of some 
categories of socioeconomic groups and towards their incomes. The objective of the health policies of the governments of Botswana and Lesotho should be to protect their citizens from catastrophic payments. The governments need to design systems of health care financing arrangements that pay special attention to protecting the poor and socially disadvantaged subpopulations.

Evidence in some developing countries has also showed that policy intervention that focuses on the supply side (treatment protocols, drug lists, and so on) might achieve more success in improving financial protection than expansion in insurance coverage. One can therefore suggest that this is worth exploring in Botswana and Lesotho if the objective of universal health, as championed by WHO, is to be achieved.

Finally, the conjecture is that the policy prescriptions being crafted in Botswana and Lesotho to reduce poverty and inequalities in health, and to spur growth should adopt an integrated and multi-sectoral approach that extends beyond the health system and health financing. These should address not only health and social care and poverty alleviation but also health-related behaviours (smoking, alcohol consumption, diet, obesity); psychosocial factors (psychosocial stressors, social support, social integration); material factors (housing conditions, working conditions, financial problems); and access to health care. The governments of Botswana and Lesotho will need to formulate explicit and comprehensive public health policies to address some or all of these simultaneously, if they are to attain the desired sustained growth and development trajectories. 


\title{
Notes
}

\begin{abstract}
${ }^{i}$ A health system is fairly financed if the ratio of total health system contribution of each household through all payment mechanisms to that household's capacity to pay (effective non-subsistence income) is identical for all households, independent of the household's health status or use of the health system (see Murray et al., 2003).

ii Catastrophic payments occur when households need to spend a significant fraction of their net income on health care, resulting in impoverishment for some of them whilst others might give up the health care needed (Cavagnero et al., 2006). Furthermore, health expenditure has been defined as catastrophic if a household's health expenditure exceeds $40 \%$ of income remaining after subsistence needs have been met (Xu et al., 2003a). There is, however, no consensus on the catastrophic threshold proportion and cut-off values that range from $5 \%$ to $20 \%$ of total household income have been reported in the literature (Berki, 1986; Wyszewianski, 1986, Flessa, 2006). Furthermore, it is not only high medical costs which entail catastrophic expenditures since even relatively small expenditures on health can be financially disastrous for poor households with no insurance cover (WHO, 2000).

iii Fairness in financing ratio is the ratio that relates total household expenditure for health through general taxes, social health insurance contributions, private health insurance premiums, and out-of-pocket payments, to the household's capacity to pay; where the capacity to pay of a household is essentially its effective income minus subsistence expenditure requirements (Murray et al., 2003).

iv The data sources highlighted here have been extensively consulted during our information gathering visits to Botswana and Lesotho over the period from 15 to 21 August 2010.

$\checkmark$ Even though surveys have since been conducted in both Botswana and Lesotho since 2002/03, publicly accessible results from these were not available at the time the analyses reported in this paper were undertaken.

${ }^{v}$ Unlike in Lesotho where data on household expenditures for different goods and services were collected monthly for the whole year per household, in Botswana, data covered 12 rounds with each round representing a month. As a result, data for Botswana were not collected per household per month for the entire survey period (which is a year), but rather were collected once a month for different households in different districts for the entire survey period.
\end{abstract}

\section{References}

Alam, A., M. Murthi, R. Yemttsov, E. Murrugarra, N. Dudwick, E. Hamilton, and E. Tiongson. 2005. Growth, Poverty, and Inequality: Eastern Europe and the Former Soviet Union. Washington, D.C.: The World Bank.

Berki, S.E. 1986. "A look at catastrophic medical expenses and the poor". Health Affairs, 5: 13845.

Cavagnero, E, Carrin, G., Xu K, Aguilar-Rivera, A.M. (2006), 'Health Financing in Argentina: An Empirical Study of Health Care Expenditure and Utilization: Innovations in Health Financing,' Working Paper Series, No. 8.

Chama, C. 2008. "An empirical investigation of catastrophic health expenditure in Zambia". Unpublished MA thesis, University of Botswana, Botswana.

Cheelo, C., C. Chama, H. Kansembe, D. Jonsson, and K. Xu. 2009. Measuring the Distribution of Health Payments and Catastrophic Effects of Health Spending in Zambia: An Analysis of Household-Level Survey Data, Working Paper, Department of Economics, University of Zambia.

De Graeve, D. and T. van Ourti. 2003. "The distributional impact of health financing in Europe: A review”. World Economy, 26(10): 1459-79.

Flessa, S. .2006. "Catastrophic Health expenditure for health care in a low- income society: a study from Nouna District', Burkina Faso”. Bulletin of the World Health Organization, 84:(1). 
Frenk, J., R. Lozano and M.A. González-Block. 1994. “ (Economy and health: proposals for the progress of the National Health System in Mexico-Final Report). Mexican Health Foundation, Mexico City, Mexico.

Gakidou, E., Lozano, R., Gonzalez-Pier, E., Abbot-Klafter, J., Barofsky, J.T., Bryson-Cahn, C., Feehan, D.M., Lee, D.K., Hernadez-Llamas, H. and Murray, C.J.L. (2006), Health System Reform in Mexico 5 -assessing the effect of the 2001-06 Mexican Health Reform: an interim Report Card.' Lancet, 368(9550): 1920 - 1935.

Gonzalez, P.E. and S. Parker. 1999. "Equity in the finance and delivery of health care: Results from Mexico”. EquiLac/IHEP project, Mexico.

Habicht, J., K. Xu, A. Couffinhal and J. Kutzin. 2006. "Detecting changes in financial protection: creating evidence for policy in Estonia". Health Policy and Planning, 21(6): 421-31.

Hotchkiss, D.R., J.J. Rous, K. Karmacharya and P. Sangraula. 1998. "Household health expenditures in Nepal: Implications for health care financing reform". Health Policy Planning,13: 4, pp.371-83.

Kawabata, K., Xu, K. and Carrin, G. (2002), Preventing impoverishment through protection against catastrophic health expenditure', Bulletin of World Health Organization, vol. 80 No.8.

Knaul, F.M., H. Arreola-Ornelas, O. Mendez-Cariado, C. Bryson-Cahn, J. Barofsky, R. Maguire, M. Miranda and S. Sesma. 2006. "Health system reform in Mexico 4. Evidence is good for your health system: Policy reform remedy to catastrophic and impoverishing health spending in Mexico". Lancet, 368(9549): 1828-41.

Lasprilla, E., C. Obando, E. Encalad and C. Lasprilla. 1999. "Health sector inequalities and poverty in Ecuador". In E. Greene, V. Zevallos and R. Suárez. eds., Health Systems Inequalities and Poverty in Latin America and the Caribbean. Results of the PHO/UNPD/ World Bank, EquiLAC/IHEP project. Washington, D.C: The World Bank.

Limwattananon, S., V. Tangcharoensathien, and P. Prakongsai. 2007. "Catastrophic and poverty impacts of health payments: results from national household surveys in Thailand". Bulletin of the World Health Organization, 85(8): 600-06.

Merlis, M. 2002. "Family out-of-pocket spending for health services: a continuing source a continuing source of insecurity". At http://www.cmwf.org/programs/insurance/merlis _oopspending_509.pdf (accessed 15 December 2007).

Murray, C.J.L., F. Knaul, P. Musgrove, K. Xu and K. Kawabata. 2003. "Defining And Measuring Fairness In Financial Contribution To The Health System”. GPE Discussion Paper Series. WHO Working Paper No.24 EIP/GPE/FAR. World Health Organization, Geneva.

O’Donnell, O., E. van Doorslaer, R. Rannan-Eliya, A. Somanathan, S.R. Adhikari, B. Akkazieva, D. Harbianto, C.C. Garg, P. Hanvoravongchai, A.N. Herrin, M.N. Huq, S. Ibragimova, A. Karan, S.M. Kwon, G.M. Leung, J.F. Lu, Y. Ohkusa, B.R. Pande, R. Racelis, K. Tin, K. Tisayaticom, L. Trisnantoro, Q. Wan, B.M. Yang. and Y. Zhao. 2008.. "Who pays for health care in Asia?" Journal of Health Economics, 27(2): 460-75. 
Pannarunothai, S. and A. Mills. 1997. "The poor pay more: health- related inequality in Thailand”. Social Science Medicine, 44: 1781-90.

Pradhan, M. and N. Prescott. 2002. "Social risk management options for medical care in Indonesia". Health Economics, 11: 431-46.

Ranson, M.K. 2002. "Reduction of catastrophic health care expenditures by a community-based health insurance scheme in Gujarat, India: current experiences and challenges". Bulletin of the World Health Organization, 80(8): 613-21.

Russell, S. 2004. "The economic burden of illness for households in developing countries: A review of studies focusing on malaria, tuberculosis, and human immunodeficiency virus/acquired immunodeficiency syndrome". American Journal of Tropical Medicine and Hygiene, 71(Supp. 2): 147-55.

Skarbinski, J., K. Walker, L.C. Baker, A. Kobaladze, Z. Kirtava and T.A. Raffin. 2002. "The burden of out-of-pocket payments for health care in Tbilisi, Republic of Georgia". Journal of the American Medical Association, 287: 1043-49.

van Doorslaer, E., O. O’Donnell, R.P. Rannan-Eliya, A. Somanathan, S.R. Adhikari, C.C. Garg, D. Harbianto, A.N. Herrin, M.N. Huq, S. Ibragimova, A. Karan, C.W. Ng, B.R. Pande, R. Racelis, S. Tao, K. Tin, K. Tisayaticom, L. Trisnantoro, C. Vasavid and Y. Zhao. 2006 "Effect of payments for health care on poverty estimates in 11 countries in Asia: an analysis of household survey data". Lancet, 368: 1357-64.

van Doorslaer, E., O. O’Donnell, R. Rannan-Eliya, A. Somanathan, S.R. Adhikari, CC. Garg, D. Harbianto, A.N. Herrin, M.N. Huq, S. Ibragimova, A. Karan, T.J. Lee, G.M. Leung, J.F. Lu, C.W. Ng, B.R. Pande, R. Racelis, S. Tao, K. Tin, K. Tisayaticom, L. Trisnantoro, C. Vasavid. and Y. Zhao. 2007. "Catastrophic payments for health care in Asia". Health Economics, 16(11): 115984.

van Doorslaer, E. and A. Wagstaff, 1992. "Equity in the delivery of health care: some international comparisons". Journal of Health Economics, 11(4): 389-411.

Wagstaff, A. and E. van Doorslaer. 2003. "Catastrophe and impoverishment in paying for health care: With applications to Vietnam 1993-98”. Health Economics, 12: 921-34.

Wagstaff, A., E. van Doorslaer, H. van der Burg, S. Calonge, T. Christiansen, G. Citoni, U.G. Gerdtham, M. Gerfin, L. Gross, U. Hakinnen, P. Johnson, J. John, J. Klavus, C. Lachaud, J. Lauritsen, R. Leu, B. Nolan, E. Peran, J. Pereira, C. Propper, F. Puffer, L. Rochaix, M. Rodriguez, M. Schellhorn, G. Sundberg, and O. Winkelhake 1999. "Equity in the finance of health care: some further international comparisons". Journal of Health Economics, 18(3): 263-90.

World Bank. Technical Note No. 6: Concentration curves, and Technical note No.7: the concentration index. In Quantity techniques for health equity analysis, World Bank, Washington,DC. Accessed on January 20, 2008 from http://siteresources. worldbank.org/INTPAH/Resources/Publications/4598431195594469249/HealthEquityFINAL.pdf

World Bank. 2005. World Development Report 2006: Equity and Development. Washington,D.C.: The World Bank. 
WHO (World Health Organization). 2000. Macroeconomics and Health: Investing in Health for Economic Development. Report of the Commission on Macroeconomics and Health. Geneva: World Health Organization.

Wyszewianski, L. 1986. "Families with catastrophic health care expenditures". Health Services Research, 21: 617-34.

Xu, K., D.B. Evans, K. Kawabata, R. Zerandini, J. Klavus and C.J.L. Murray. 2003a. "Household catastrophic health expenditure: a multi-country analysis". Lancet,362: 111-17.

Xu, K., J. Klavus, D.B. Evans, P. Hanvoravongchai, R. Zeramdini R. and C.J.L. Murray. 2003b. "The impact of vertical and horizontal inequality on the fairness in financial contribution index". In C.J.L. Murray and D.B. Evans, eds., Health Systems Performance Assessment: Debates, Methods and Empiricism. Geneva: World Health Organization. ET AL 2003A AND 2003B IN TEXT

Xu, K., B. David, D.B. Evans, P. Kadama, J. Nabyonga, P.O. Ogwang, P. Nabukhonzo, And A.M. Aguilar. 2005. "Understanding the impact of eliminating user fees: Utilization and catastrophic health expenditures in Uganda". Social Science and Medicine,62: 866-76.

Xu, K., D.B. Evans, G. Carrin, A.M. Aguila-Rivera, P. Musgrove, and T. Evans. 2007. "Protecting households from catastrophic health spending". Health Affairs (Project Hope), 26(4): 972-83. 